\title{
Confronting the Need for Conceptual Change in Pre-Service Science Education
}

\author{
Marc S. Schwartz ${ }^{1}$, Irwin I. Shapiro ${ }^{2} \&$ Bruce Gregory $^{2}$ \\ ${ }^{1}$ University of Texas at Arlington, Arlington, TX, USA \\ ${ }^{2}$ Harvard-Smithsonian Center for Astrophysics, Harvard University, Cambridge, MA, USA \\ Correspondence: Marc Schwartz, SW Center for Mind, Brain and Education, University of Texas at Arlington, \\ Arlington, TX 76019, USA. E-mail: schwarma@uta.edu
}

Received: April 24, 2013 Accepted: August 19, 2013 Online Published: September 22, 2013

doi:10.5539/hes.v3n5p11 URL: http://dx.doi.org/10.5539/hes.v3n5p11

\begin{abstract}
During a five-year period the authors taught over 100 students in a graduate course (The Nature of Science) counting toward teacher certification at the Harvard Graduate School of Education. Despite the fact that students had undergraduate degrees in the sciences, most of them found the application of models in science challenging and the epistemological consequences unsettling. Moreover, students found it especially difficult to use a model to correctly generate predictions, which was starkly illustrated with the application of Archimedes' principle during our unit on floating and sinking. We examine the deceptive belief that student success with algorithms and word problems leads to conceptual understanding as well as the conceptual change necessary to understand the relationship between evidence and inference as explored in the nature of science course. Considering the apparently strong science backgrounds of our students, we doubt that typical pre-college students can achieve the goals described in the National Science Education Standards in the short time typically allotted for their science studies. We explore the issues students face in "understanding" science as well as the impact of science education on students and teachers, and implications for policy makers and pre-service programs.
\end{abstract}

Keywords: science education, scientific literacy, science teachers, science instruction, nature of science, conceptual change

\section{Introduction}

Over the course of five years the authors taught a one-semester course entitled, "The Nature of Science" to over a hundred students at the Harvard Graduate School of Education. Our students were mostly candidates in a one-year masters degree program that also provided teaching certificates in secondary-school science. Early on we recognized, as other researchers have observed across cultures and contexts, that largely because of prior training, students don't understand the nature of models in science, or conflate Nature's behavior with the models (or theories) created by scientists to describe and predict the way Nature behaves (Brown \& Clement, 1989; Coll, France, \& Taylor, 2005; Gericke, Hagberg, \& Jorde, 2013; Gilbert, Pietrocola, Zylbersztain, \& Franco, 2000; Grosslight, Unger, Jay, \& Smith 1991; Philippi, 2010; Treagust, Chittleborough, \& Mamiala, 2002). Some conflation is inevitable, but nonetheless, to understand science one must clearly distinguish between evidence (Nature's behavior) and inference (our models of Nature's behavior). We also learned that while our students were skilled in using certain algorithms they had difficulty applying the models that underlie the algorithms, a discovery well documented by many researchers (i.e., students could be quite skilled at solving problems involving an algorithm without understanding the conceptual nature of the problem) (Arons, 1990; Hestenes, 1998; Loverude, Kautz, \& Heron 2003; Kim \& Pak, 2002; McDermott \& Redish, 1999; Schwartz \& Sadler, 2007; Doucerain \& Schwartz 2010). (Note 1)

In response to these two observations, our goal was to overcome student difficulties by emphasizing (1) the distinction between evidence and inference, and (2) the importance of models in science. Both goals fall within a broader topic, the nature of science ("NOS" hereafter), which has been the central focus of science education since the beginning of the 20th century (Abd-El-Khalick \& Lederman, 2000). However, as important as these goals may be to science education, meeting this challenge has not been easy (Abd-El-Khalick \& Lederman, 2000). Thus, our objective was to create a curriculum that would address both goals through a process that promoted conceptual change- a theoretical framework advanced and used by numerous authors (Chi \& Roscoe, 
2002; Chinn \& Brewer, 1993; diSessa, 2006; Limon, 2001; Posner et al., 1985; Strike \& Poster, 1992; Scott, Asoko, \& Leach, 2007; Taber, 2009; Turcotte, 2012; Tyson et al., 1997; Vosniadou, Baltas, \& Vamvakoussi, 2007; Vosniadou, 2008).

Although success with this approach has been inconsistent (Chinn \& Brewer, 1993; 1998; Howe, Devine, \& Tavares, 2013; Vosniadou et al., 2007), we believed we had the ideal context to address the concerns of these authors and to support conceptual change. Our students had outstanding undergraduate records. They had earned bachelor degrees in biology, chemistry, engineering, general science, or physics from prestigious post secondary institutions. Given their backgrounds and their expressed desire to improve science instruction, we anticipated that once our students recognized that their skill with algorithms masked their inability to use models to solve conceptual problems, this revelation would disturb and motivate them to advance their understanding.

Our curriculum was built upon the presentation of several anomalous (or counter-intuitive) events (Limón, 2001) to expose the gap between their expertise with algorithms (such as density = mass/volume) and their murkier understanding of the concepts summarized in such equations. As we had assumed, our students were disturbed by their incomplete understanding, and most were highly motivated to resolve their questions through experimenting. However, to our surprise, their interest was often short-lived; many became frustrated with their inability to quickly close the algorithm-conceptual gap. For some of our students, their anxiety with this experience altered their goals about wanting to understand science.

Our students' struggles appeared during a unit on floating and sinking ("F\&S" hereafter), a topic we chose because of its popularity in many K-12 curricula. This article explores the nature of our pre-service students' difficulty in understanding the conceptual framework that underlies the algorithms they learned in school, but more importantly, we discuss the daunting challenge that students and teachers are facing in meeting national science standards, first summarized by the National Research Council (1996) and more recently revised in the national framework for K-12 Science Education (National Research Council, 2012). Our ultimate goal was to help students understand NOS so that they could confront conceptual change in their learning process as well as their student's.

\section{Literature Review}

From the beginning we assumed that if science teachers did not understand the distinction between evidence and inference they were missing a fundamental aspect of science (almost its definition), and as a consequence would be ill prepared to teach science effectively. Our attempt to clarify this distinction was based upon a long and rich history of education research on promoting conceptual change, beginning with Kuhn's (1962) exploration of conceptual change among professional scientists, to Posner, Strike, Hewson and Gertzog's (1982) framework to support conceptual change in students, to decades of research in defining, understanding and promoting conceptual change summarized in the International Handbook of Conceptual Change (Vosniadou, 2008) and soon to be released second edition in 2013.

The nature of conceptual change as observed in professional scientists and learners share some superficial features, most generally in the transition from one conceptual framework to another to better explain natural phenomena. For professional scientists this process can be challenging especially when allegiance to one conceptual framework (or model) may have been developed over a career or lifetime. Any change in an original model, if deemed necessary, can require enormous energy in order to reevaluate existing data, interpret new data, or direct or re-direct attention to other aspects of the phenomenon being studied. This last point is a central concern in Kuhn's (1962) original work, and described in detail in Le Grand's (1988) analysis of why the Continental Drift theory was so contentious for so long.

However, conceptual change as addressed here concerns the experiences of learners, where educators and curricula focus on how to help students move closer to the models scientists are currently using (Taber, 2009). In this context educators find that students often enter the conversation with pre-existing ideas about the world, and thus the role of science education is to bring student ideas more in line with accepted scientific models. This has not been a trivial task and has occupied much of the literature since the early 70's (Taper, 2009). In the early 80's Posner and his colleagues (1982) introduced a set of preconditions for supporting conceptual change in learners that has remained an important framework in educational research (Scott et al., 2007; Vosniadou, 2008). The framework highlights four pre-conditions, of which the first three have been of much interest to educators:

1. Students must note that their present view is not working and that some action is necessary (e.g., reorganize, restructure or change existing ideas).

2. Students must understand alternative views offered as substitutes for existing ideas. 


\section{The alternative view must appear reasonable.}

4. The alternative view should offer a promising framework for addressing new questions.

These steps summarize in part an even older history within the cognitive sciences concerning the nature of learning. At the heart of the first precondition is Piaget's foundational idea of disequilibrium - the tension individuals face when trying to adapt their current resources (i.e., skills) to novel situations or to the demands of new problems. Piaget viewed disequilibrium as an important state leading to new and potentially more powerful equilibrium states through a process of auto-regulation (Piaget, 1964; 1985). In science, disequilibrium, or more generally, cognitive conflict, is foundational to how models change once the weight of evidence casts doubts on less robust models. Even though this process can be contentious (Kuhn, 1962; Le Grand, 1988), cognitive conflict among scientists tends to maintain the pressure on finding better models of nature (Dunbar, 1995).

Generating disequilibrium or cognitive conflict for students is a different matter as students are not necessarily aware of any conflict between their ideas and those of scientists. As a result educational researchers have looked for ways to provoke cognitive conflict in lessons to challenge students to re-examine their ideas (Champagne, Gunstone, \& Klopfer, 1985; diSessa, 2006; Lee \& Byun, 2012; Limon, 2001; Vosniadou; 2008). While the desire to resolve a problem creates the opportunity to improve one's understanding of nature, educators continue to face the daunting challenge of designing curricula to support conceptual change. Over the last three decades many authors have focused on formalizing and adapting the process to classrooms (Cosgrove \& Osborne, 1985; Howe et al., 2013; Ivarsson, Schoultz, \& Saljo, 2002; Lee \& Byun, 2012; Nussbaum \& Novick, 1982; Turcott, 2012; Vosniadou, 2008). Other researchers have focused on other areas such asthe importance of the student's prior conceptions(Driver et al., 1985; Sadler, 1992; diSessa, 2008), the value in creating experiences that generate cognitive conflict in classrooms (Lee \& Byun, 2012;Vosniadou, 2007) or the challenges students face in re-organizing their views in light of the dissonance they experience in lessons designed to create cognitive conflict (Chi \& Roscoe, 2002; Chin \& Brewer, 1993, 1998; Lee \& Byun, 2012; Howe et al., 2013).

Researchers continue to explore how the process unfolds (Suping, 2003; Vosniadou et al., 2007; Vosniadou, 2008) and the approaches or strategies useful to support the process (Chinn \& Brewer, 1998; Hewson \& Hewson, 1984; Howe et al, 2013; Vosniadou, 2008; Durmus \& Bayraktar, 2010). Sometimes refereed to as the classic framework (Vosniadou, 2008), Posner and colleague's (1982) original framework remains a centerpiece of discussion as researchers continue to search for mechanisms that support and promote conceptual change in students. Limón (2001) noted that: "Three kinds of instructional strategies can summarize many of the instructional efforts made to promote conceptual change: (a) the induction of cognitive conflict through anomalous or unanticipated data; (b) the use of analogies to guide students' change; and (c) cooperative and shared learning to promote collective discussion of ideas" (p. 358). Howe, Devine and Tavares (2013) summarized three potential issues with the classic framework when researchers reported limited success with an intervention: “(a) experiments often fail to generate the requisite data; (b) Posner et al.'s (1982) [first] three conditions may be necessary, but they are insufficient; and, (c) cognitive limitations eclipse the significance of experimental evidence" (p. 865). The last point has been a central focus in the cognitive sciences to understand cognitive limitations from a developmental point of view and to explain the movement from disequilibrium to equilibrium as a dynamic process that evolves as the mind and brain mature (Fischer \& Bidell, 2006; Schwartz, 2009).

Beyond the observations of Howe and her colleagues (2013), researchers have also raised the concern that cognitive conflict as a general classroom strategy overlooks the impact of developmental, motivational, or societal pressures that students face (Pintrich, Marx, \& Boyle, 1993; Vosniadou, 2007), specifically that any lesson designed to generate cognitive conflict might not be meaningful to students (Chinn \& Brewer, 1993, 1998; Lee \& Byun, 2012). To meet these challenges we felt that by creating a strong connection between scientific models and the nature of knowledge within the context of teaching and learning (as our students would face in their careers as teachers), as well as supporting the metacognitive work necessary to mediate the challenge our students faced in our course, we would address the fundamental concerns well summarized more recently by Vosniadou (2007). And while Lee and Byun (2012) agree with the concerns raised by Vosniadou and others, they found that cognitive conflict remains a valuable strategy for initiating the learning process. We felt that our students were developmentally prepared to meet the challenges of our course, motivated to be successful, interested in science, and ready to improve their skills on behalf of their future students.

\section{Procedure}

Classes each year averaged around 20 students with roughly equal number of women and men. Our approach emphasized Limón's (2001) first strategy to launch the lesson, and the third to maintain interest and support 
conceptual change. The general pedagogy was to offer an anomaly or discordant event that captured the students' attention and then provided students the opportunity to question their assumptions.

Because success with the anomaly approach depends on how well educators consider significant issues such as student motivation, epistemological beliefs or social factors (Limón, 2001), we transitioned from the anomaly to a longer period of exploration to discuss the underlying conceptual ideas in Archimedes' principle. Students had the time to explore the nature of their motivation, their changing ideas, and the implications for their teaching. Our approach with the F\&S unit required eight classes of one-and-a-half hours each totaling 12 hours of instruction spread over four weeks.

Our introduction to the unit on F\&S was itself an anomaly for students. Each year we began the unit with two multiple-choice questionnaires. Each targeted a different kind of knowledge about F\&S. Questionnaire I (Appendix A; hereafter, QI) had six questions that could be answered by solving for one of the variables in the relationship density $=$ mass/volume or by recalling knowledge from eighth grade science (e.g., water has a density of $1 \mathrm{gm} / \mathrm{cm}^{3}$ ). Questionnaire II (Appendix B; hereafter, QII) had ten problems that were conceptual in nature. For example, students decided whether a cruise ship could float in a bathtub that was only slightly larger than the ship itself. These problems were adapted from conceptual problems found in Thinking Physics (Epstein\& Hewitt, 1981; Epstein, 2009),also found in various forms in Conceptual Physics (Hewitt, 2011) used over the last 30 years through 11 editions in introductory physics courses in secondary and post-secondary institutions around the world.

Our purpose was to demonstrate to students that there was a striking difference between successfully manipulating variables in an algorithm associated with density and the ability to address problems that require the application of a relatively simple model (in this case Archimedes' principle) to predict whether objects will float or sink. By presenting to students their answers to the first questionnaire we confirmed the high degree to which they agreed on each answer. However, class results for the second questionnaire highlighted the large range of answers to (and perhaps high degree of confusion about) this new set of questions. This anomaly (i.e., the difference in results between the questionnaires) served as an opportunity to stimulate the students to further investigate the questions in QII and their understanding of F\&S.

Our challenge was to create questions that students would not judge as too simple, and therefore insignificant, or too challenging and therefore beyond their ability to address. The importance of this range, which would allow students to be active, focused, and engaged, has been addressed from a variety of theoretical perspectives- the Zone of Proximal Development (Vygotsky, 1978), functional-optimal performance (Fischer \& Bidell, 2006), and Flow (Csikszentmihalyi \& Rathund, 1998). During the first two years that we taught the course, the questionnaires evolved in minor ways, mostly to increase the clarity of the questions. During the final three years of the course, the questionnaires remained the same, and each year all students verified that they understood the intent of each question.

We capitalized on the tension created by the different levels of agreement of answers on the two questionnaires by allowing students to confront the conceptual issues emphasized in QII in open-ended experiments. Under further inspection students recognized that the questions also evoked anomalous situations when they realized their intuitions about the answers were undependable. For example, students were drawn to Question 9 (Appendix B) describing a glass filled to the brim with water and ice. In this problem when looking at the glass from the side, clumps of ice appear above the water line, and the ice descends down the glass but does not touch the bottom. Most of our students felt certain that when the ice melted the water would overflow. They cited experiences at restaurants where they observed this phenomenon, and described situations where they observed the same effect while enjoying a drink outdoors. The observable fact is that they are wrong. We anticipated that this experience would help them appreciate the role that both observations and models play in science. Students initially invested approximately two full classes investigating in small self-formed groups the questions that interested them with relevant materials we provided (plastic tubs, graduated cylinders, blocks of materials, scales, ice, water, etc.). The instructors moved separately from group to group to help students to determine what they observed as well as the reliability of their observations.

During the first year of the project all classes were videotaped for later inspection and discussion between authors. The lead author took notes for each class, which helped in exploring in further detail specific events, which seemed critical in the students' experience. (Note 2)

After students explored answers to questions on QII, the class entered a longer feedback phase. We introduced Archimedes' principle and focused on how this model could be used to predict the results of their observations. We also asked students to predict outcomes in new contexts. We emphasized the key role that models play in 
"making sense" of the world, and noted the limitations of models revealed by deeper probing into Nature's behavior in the F\&S context. In follow-on classes we discussed the meaning of the terms that students had used to describe their observations (e.g., mass, weight, volume, force, etc.). Along with Archimedes' principle we gave students the time to identify those problems that could be solved with this principle. We then had the students return to experimenting to check the solutions obtained using this model. As homework, students wrote down their predictions based on the model and compared them with the observations they made during their experimenting. For example they would use Archimedes' principle to scaffold a description of what should happen to the level of the water in the pool once the anvil was removed from the canoe and dropped into the pool Keeping their observations from class in mind, they had to construct a narrative with Archimedes' principle as the backbone to their argument. They shared their results during the next class.

During the third year we taught the course, we introduced and subsequently retained an additional and final form of feedback. We concluded the F\&S unit with a demonstration representing a new problem that could be answered by applying Archimedes' principle. In front of the class, we balanced a partly filled glass of water on a triple-beam balance. (Note 3) We asked the class: If one of us placed his index finger into the water, without causing an overflow, would the glass move down, or up, or stay as it is? The problem was posed to the entire class, with the students having the opportunity to listen to their peers' responses. We required students at a minimum to predict an outcome and, if they felt comfortable, to also describe their reasoning.

\section{Results}

After students completed QI, we created a histogram showing the number of students who had chosen each response; we did not provide the correct answers. Students examined the distribution of responses, and decided in each case if there were strong preferences for particular answers. (Table 1 displays the sums of these distributions for the last three years in which we taught the course. We did not retain data from the first two years.)

Table 1. Questionnaire I: understanding density

\begin{tabular}{cllll}
\hline Question No. & A & B & C & D \\
\hline 1 & 2 & 2 & 52 & 0 \\
2 & 54 & 0 & 0 & 2 \\
3 & 49 & 3 & 0 & 4 \\
4 & 55 & 1 & 0 & 0 \\
5 & 50 & 3 & 1 & 2 \\
6 & 7 & 46 & 2 & 1
\end{tabular}

Description: These results were collected during the final three years that the authors taught this course. The average score for QI during this period was 91\%.

Each year students looked at the results, and smiled or gently nodded their heads in a modest affirmation that these answers were obvious. There was nothing here that surprised them - the density of water was still 1 $\mathrm{gm} / \mathrm{cm}^{3}$; objects with a density greater than $1 \mathrm{gm} / \mathrm{cm}^{3}$ sank; and students only needed simple algebra to calculate a missing variable in an equation like $\mathrm{d}=\mathrm{m} / \mathrm{v}$. We asked students if the results from QI adequately supported the assumption that they understood density and issues concerning F\&S. We interpreted their silence (and nods of affirmation) to reflect their confidence and comfort with the topic, a conclusion not supported by the later notable difference in student reactions to QII.

We next presented QII to our students. Not only did the problems in QII differ dramatically from those in the first, so did the distribution of student answers (Table 2). Students did not need training in statistics to appreciate the implications of the wider variation in their answers in QII. (Again the data is here pooled from the last three years we taught the course.) 
Table 2. Questionnaire II: understanding floating and sinking

\begin{tabular}{cllll}
\hline Questions & A & B & C & D \\
\hline 1 & 9 & 42 & 6 & x \\
2 & 22 & 11 & 4 & 20 \\
3 & 13 & 36 & 6 & 2 \\
4 & 2 & 45 & 5 & 5 \\
5 & 39 & 7 & 11 & x \\
6 & 14 & 32 & 11 & x \\
7 & 9 & 22 & 26 & x \\
8 & 10 & 21 & 26 & x \\
9 & 30 & 9 & 18 & x \\
10 & 16 & 11 & 29 & x
\end{tabular}

Description: The average score on Questionnaire II during the final three years of the course was $49 \%$. An " $x$ " in column D signifies that there were only three choices for the answer of the corresponding question. The average score if answers were chosen randomly would be approximately $32 \%$

Students recognized the problem raised by the contrasting trends that they observed in the responses to the two questionnaires. QII created a problem they could not readily dismiss. They, as a group of future science teachers, were confronting a new dilemma - the possibility that there was a significant difference between what aspiring science teachers thought they understood about F\&S and what they had yet to understand about F\&S. Each year we used both questionnaires and each year students responded in a similar fashion. They usually studied the results from QII in silence. Slowly some expressed their surprise or their concern with this experience. Some students speculated on the cause of the contrast. A few would decry QII, claiming that it had trick questions or that this questionnaire had little to do with the other. Although denying the "data" appears to be a common reaction to anomalous data (Chinn \& Brewer, 1998), this reaction was short-lived. Most students began asking for the "correct" answers and explanations to QII's questions. When we responded by inviting students to first explain their answers, they again became silent. Many struggled to articulate their reasoning. Even students who had answered questions correctly were often unsure why they chose a particular answer.

We anticipated that students would find the results not only disturbing but also compelling. We hoped that the second phase of our teaching approach, confronting the anomaly through experiments and discussion, would not only help students see beyond the algorithm-based approach to science, with which they were already successful, but also help them appreciate the investment of time necessary to more fully understand models used in science. The cornerstone of this understanding would be our students' success in recognizing the complementary roles of Nature and our models of Nature, which should serve as a context for students using models to solve specific problems.

\subsection{The Role of Student Experiments}

Not only were our students surprised about the lack of consensus among their peers, they were curious about the problems they found in QII. For example, each year students were drawn to question 10 - the canoe in a swimming pool (see Appendix B). The canoe contains an iron anvil, which is then removed from the canoe and lowered into the pool. Prior to this action, the level of water in the pool is noted. The student's challenge is to predict the level of the water in the pool once the anvil is sitting on the bottom of the pool. Did the water level go up, down, or not change?

Our students initially discussed what they thought and then tried to determine the answer experimentally. Initially we provided everything they needed except, of course, the answer (which most felt they needed to validate their results). We also invited the students to determine empirically with the same equipment Nature's answers to any of the other questions. Students chose the questions on which they wanted to work and formed their own small groups to investigate. The groups were fluid within and between classes. Some students stayed focused on one problem for several class periods while other students moved from group to group and question to question. In our individual interactions with groups we asked open-ended questions focusing on what they had discovered, how they could ascertain to what extent their findings were reliable, and what their findings meant to 
them. As a result of carrying out their own experiments, students confronted additional issues common to work in science such as experimental design, reproducibility of results, and (concomitantly) measurement error. Working out these issues required time but students profited in two additional ways: They were learning in a context in which these issues were no longer just general concerns in science; and, these issues had become relevant factors in the students' interpretations of their own observations.

After several class periods devoted to experimenting, we asked students about the answers to each of the questions. Students unanimously concluded that there was indeed only one correct answer to each question. However, they were still not satisfied. The students now wanted to know why the answers were what they were.

\subsection{The Role of Models}

As we had not initially given students a formal model with which to frame an "explanation" of their observations, they found their initial experiments frustrating. We invited students to share their results, their understanding, and any confusion they had. Sometimes a group's experimental results didn't agree with what other students felt they knew. For example, in response to question 9 on QII, one group said that they had all bought drinks at McDonalds and claimed to have seen the level of water go down as the ice melted. The answer was so obvious that they saw no need to experiment. In other cases the students' experiments generated new problems. One student speaking for his group said, "We can answer questions about density, but we can't answer questions about floating and sinking. It seems that the math isn't useful." After this discussion period we introduced Archimedes' principle as a model to "explain" what they had observed: an object that floats in a fluid displaces its weight of that fluid, and an object that sinks displaces its volume of that fluid. This principle served as our introduction to models.

We then asked students to revisit the questions in both questionnaires with Archimedes' principle in mind. Again, in small groups, students determined where the principle had the most potential for "explaining" their observations. Students had to coordinate variables such as weight (of the object or of the liquid displaced), the volume of the same solid or liquid in question, and the state of the object (floating or sunk) into one coherent story. Each group started with one of the questions, and attempted to explain the observations they made in terms of the principle. Most students struggled with this task and the outcome.

Despite any success in using Archimedes' principle, students often pointed out that their explanations did not "count" as an answer because: "The model only tells you whether the object will sink or float; it doesn't deal with situations in transition [where the object is in the process of sinking]; and, it [the model] is not process oriented, it is outcome oriented." They were still asking, "Why?" "Why do objects that float displace their weight in water? Why did the water level change? Why does the ship float in the bathtub? Why do ships float at all? What is holding up the ship?"

Other students still felt that there was something missing even though they now had an empirical answer for each question and a model that enabled them to predict the answer. When we asked them what more they wanted, they were uncertain. One student said, "I can predict that every time I sit a bottle on a table it won't sink into the table, but I don't understand why." Another student wrote after the activity, "Once again, I feel a need for a right answer. An answer key." Both students were looking for more closure than the models they were using could provide.

For other students the experience was unsettling because they realized that they did not understand their peers' explanations when they attempted to describe their use of Archimedes' principle to address the questions on QII. Some, but not all, students claimed that when their peers explained how they used the principle it sounded like a lecture, which they had a difficult time following. In one case, a student stopped half way through his explanation of how the principle could be used, and claimed that his answer made sense to him when he wrote it, but not at the moment.

\subsection{The Role of the Final Demonstration}

During the last class of the F\&S unit we offered our students one final opportunity to apply Archimedes' principle in a new context. We balanced a partly filled glass of water on a triple beam balance and asked students: If one of us placed his index finger into the water, without causing an overflow, would the glass move down, or up, or stay as it is? We then recorded all student predictions and comments. No student predicted that the glass would rise. Roughly half the class claimed that the glass would go down for one of three reasons: "Buoyancy was involved [but not sure how]," "Objects in water displace their weight [so the scale would reflect this]," "The water supports part of the weight [of the finger]." The rest of the class felt that the glass would not move. When reasons were offered, most focused on students' (apparent) knowledge of forces and buoyancy: "all the weights 
cancel [each other]," "All the forces are still equal," "You are exerting an opposite and equal force; therefore, nothing will happen [to the glass]," "[The change in] volume increases the buoyant force [as the finger descends in the water] which supports the finger," "You [the person with the finger in the water] are still holding all the 'force,"” "You are exerting a force to hold up the finger... unless it was cut off. In this case [the finger is attached to your hand and thus] your finger is suspended," "The finger is still attached [so there should be no change]."

Even though students had invested nearly six class hours over a span of two weeks thinking about and working with Archimedes' principle, nearly all students reverted to other "knowledge" about forces and buoyancy, which was insufficiently developed and consequently unhelpful to them. We encountered such responses each of the three years that we ended the F\&S unit with this demonstration. Even though we recognized that predicting the outcome of this demonstration was hard for the students because the finger was attached to the body and served as a "distractor," we were struck by the fact that of all the responses, only one made reference to Archimedes' principle. Clearly, students still had difficulty seeing and/or using the principle as a tool to interpret their observations, a tool that was, moreover, one that could be applied in this and other contexts.

\section{Discussion}

We found that almost all of our students, all of whom had majored in science, did not understand the basic structure of science. We witnessed our students' struggles as they attempted to reconcile their own view of an acceptable answer to "why" with a scientists' view- a scientist's answer to questions regarding why Nature behaves as it does, is simply to note that he/she can only know (i.e., find out) how Nature behaves, never why. Students also struggled with the implications of the fact that in our universe, scientific models may be limited in their ability to describe and predict Nature's behavior. Our students reminded us that understanding both the NOS and the models used in science is a difficult, often counter-intuitive, challenge. Students often require years to successfully use models to solve conceptual problems. Our students were unprepared for this level of philosophical and practical engagement with models. We concluded that it is no accident that most science programs focus on creating competency with algorithms instead of competency in solving problems using models, as required in QII.

Our students' experience clearly illustrated the "theory-practice" problem observed by McGoey and Ross (1999) who found that their science teacher interns were more interested in the mechanics of teaching ("how to") instead of the theory behind the mechanics ("how come"). As reasonable as this view is for any apprentice, the authors, like us, found that supporting a transition in student perspective from "how to" to "how come" was not easy or comfortable for the interns.

The final demonstration helped us to recognize that our students had experienced an educational problem of considerable importance - the challenge of transferring ideas to a new problem or context. This issue has been explored extensively in the literature on transfer and the role of context (Brown, Collins, \& Duguid, 1989; Carpenter, 2012; Corte, 2012; Fischer, Bullock, Rotenberg, \& Raya, 1993; Lave, 1993; McKeough \& Lupart, 1995; Potgieter, Harding, \& Engelbrecht, 2008; Rogoff, 1990; Salomon \& Perkins, 1989; Willems, 2005). In our case students struggled to recognize whether Archimedes' principle was useful in a new context, and encountered difficulty in following their peers' reasoning as they described how they used the principle. Both situations required new levels of understanding, beginning with the need to compare and contrast contexts and explanations. Our students also needed to consider the extent to which the context could change before the principle lost its explanatory or predictive potential, or explain why the model was no longer useful in the new contexts they experienced or imagined. These steps mirror the approach that Brown and Clement (1989) used in helping students employ "bridging analogies" to transition from their initial and personal views of the natural world to accepted scientific views. Even though our primary goal was to explore the nature of science and models, and not necessarily the application of any particular model, we found that much of our work ultimately shifted to understanding one model, Archimedes', and how it applies to various problems in order to help students consider the role that models play in scientists' understanding of Nature.

After eight class meetings of experimentation and discussion, our students could determine the answers to most of the questions on the second questionnaire. The students had wrestled with issues germane to experimenting (e.g., experimental design and experimental error), and framed, to some extent, their answers in terms of the model we introduced. In discussion sessions towards the end of the unit, students were no longer asking for the answers to the questions in QII; they were questioning the usefulness of models. Given that our students began their graduate work with less comfort with these issues than we expected, we were ready to accept the progress they had made; however, to our surprise, many of our students were unhappy with the outcome of the F\&S unit. It seems that at best we gave our students "permission" to be curious. The new conceptual tool (i.e., models) that 
we thought would help them transform curiosity into understanding (i.e., learning that models, created by the human mind, could codify and predict Nature's observed behavior) was for some insufficient or unhelpful.

Many of our students were looking for a more "compelling" answer; however, they were not sure what form this answer should take. Their experience in our class of applying a model to a phenomenon was unlike the "answers" they were accustomed to, and they didn't know what they would do with this upsetting condition when facing their own students. Nearly all of our students were also simultaneously beginning internships in local schools, and some of them were about to begin units on density. Some were very concerned. Not only did they have doubts about their ability to teach in general, they had identified a new handicap. Now they wondered whether they understood the topic they were supposed to know well enough to teach it. As McGoey and Ross (1999) point out, the student teachers" "content knowledge is often their major life-saving device" in the classroom (p. 119). As a consequence, most students were relieved when we concluded the F\&S unit even though they continued to express concern that this unit had brought up more questions than answers, and some felt less certain about the subject than before.

\section{1 "Understanding” Science}

For students who were upset with the F\&S unit, we noted two conflicts. First, we had changed the nature of science for them. They were beginning to realize that if they really wanted to understand the relationship between a model and observations of the natural world, they would have to practice using the model and thinking about to which phenomena the model applies, and to which phenomena it does not. Students recognized that this task would be difficult and would require time. Second, a commitment by students to meet such a challenge appeared to undermine the education that they had already received, an education in which they were highly successful and were committed to supporting as teachers. Both observations have important implications for their students and our educational system.

One implication is the degree of commitment required to acquire the skills that allow individuals to use models to reliably predict the outcome of observations. This commitment requires time. Science educators must be wary of the insidious threat of science activities that require students merely to recognize in a word problem the correct algorithm to use, and to correctly manipulate the algorithm's variables. The literature continues to point out this problem even as new teaching techniques are explored (for example, Doucerain \& Schwartz, 2010; Kim $\&$ Pak, 2002), but the single largest threat to addressing this problem is the push to cover more material. The situation is largely driven by growing state standards (Schwartz, Sadler, Sonnert \& Tai, 2009), which hold students and teachers accountable for increasing amounts of content, which in turn reduces the time available to develop conceptual understandings. When comparing the impact of depth versus breadth of coverage of science in high school science courses, only depth of study is positively and significantly associated with higher marks in the same science disciplines in post-secondary institutions (Schwartz et al., 2009; Schwartz \& Dawson, 2011). Our students were successful at solving word problems and manipulating variables in formulas of these enterprises, and yet most floundered with the underlying model from which the algorithm emerged. When working with Archimedes' principle our students were often impatient and unhappy, and, as a result, anxious about the impact of the course on their ability to teach science. We observed a number of students each year who could not understand why they did not instantly understand how the principle applied to the problems they were studying, how it could be used to explain the phenomena of F\&S, and how to recognize its limitations.

Archimedes' principle sounds straightforward. However, applying a principle widely and successfully is the necessary foundation for recognizing how to apply a model in new contexts, distinguishing the limits of its applicability, and evaluating the model's effectiveness in addressing observed phenomena. Anyone who has become proficient in any enterprise knows that practice, especially "deliberate practice," was required to reach this degree of competence (Ericsson, Krampe, \& Tesch-Romer, 1993). Much of the literature from the cognitive sciences confirms this observation (Agung \& Schwartz, 2007; Case, 1997; Deslauriers, Schelew, \& Wieman, 2011; Fisher \& Bidell, 2006; National Resource Council, 1999; Schwartz, 2009; Siegler, 1998; Yan \& Fischer, 2002).

Most of our students needed to practice, but struggled to maintain the effort needed to reach proficiency. What we were asking of our students conflicted with what they had been practicing for years. We were asking them to dismantle the criteria that they had been using for evaluating their understanding (i.e., recalling terms, recognizing a principle, and demonstrating algebraic competency with mathematical representations of principles). Instead we were asking them to accept a new standard for understanding based upon the ability to differentiate between models and observations, and to apply the former to predict the results from the latter. This new challenge was too much for most of our students to accept at this point in their careers. 
In hindsight we understand why our students were relieved to conclude the F\&S unit. We were not only presenting them with a complex experience but with the uncomfortable realization that they would have to deal with the issue of what counts as an understanding (theirs and their students') in a time frame that required them to cover more topics than they had time to teach or even understand themselves.

The problem many of our students faced in understanding Archimedes' principle was complicated by a number of challenges. They not only needed to maintain the principle as contexts changed, they also needed to manage the dissonance created between what counted as an answer for them in the past and the way answers were presented during the course. Additionally, integrating observations with relevant models of science, while coordinating the epistemological significance for what counted as an answer, was not a trivial task. A number of developmental models underscore the mental and emotional challenge of these tasks for students (Csikszentmihalyi \& Rathunde, 1998; Fischer \& Bidell, 2007; Grannot \& Parziale, 2002; Fischer, Yan, \& Stewart, 2003).

Furthermore, given the plethora of topics to teach in one year, most of which involve models far more difficult to assimilate than Archimedes' principle, we recognize the practicality of using algorithms to summarize the concepts that typically emerge from scientific models. The formulas used to represent scientific models are easier to teach than the implications of models. The problems that require the use of these algorithms are easier to grade, and the formulas do not require open discussions about what is expected of the students. From the students' perspective these pedagogical choices require less work on their part and always lead to an unambiguous answer (which does not mean that they understand the answer, but that they recognize "the answer").

One could argue that algorithms provide students the tools they need to obtain compelling predictions about natural phenomena. However, in our experience, the students' focus appeared to be on the algebra instead of on the meaning and relationship between the variables in the formula. Teachers and curriculum designers might hope that the manipulation of variables in algorithms help students learn to use the model underlying the algorithm; unfortunately, we, like Potgieter and his colleagues (2012), encountered little evidence to support this assumption during the five years we worked with graduate students who completed science programs across the nation. We suspect that the student histories of worksheets and tests focusing on the use of the algorithm underlie their belief that the algorithm is uniquely important in science. Such a situation seriously undermines the goals of the National Standards or any other standard holding NOS as an important benchmark in achieving an understanding of science. The situation also creates significant challenges for teacher certification programs for students considering this path later in their career.

\subsection{Policy Implications for the Future}

While our primary goal was to help pre-service science educators develop a richer understanding of NOS, we also assumed that this understanding was essential for attaining the goal of effective science instruction. Although the causal relationship between these goals may be weak (Lederman, 1992), and the work in meeting these goals challenging (Abd-El-Khalick \& Lederman, 2000; Aguirre, Haggerty, \& Linder, 1990; Hipkins, 2005), we agree with Grosslight and her colleagues' (1991): "students need more experience using models as intellectual tools, more experience with models that provide contrasting conceptual views of phenomena, and more discussions of the roles of models in the service of scientific inquiry" (p. 799).

We doubt that many new science teachers are getting the opportunity to develop a working understanding of NOS or how this framework can serve them as educators. Bachkus and Thompson (2006) reported that two-thirds of American universities, responding to their national survey on pre-service science education, do not offer course work related to NOS. The authors argue that this policy reflects the importance that science-education programs place on methodology and content courses, as well as the lack of time in one-year pre-service programs.

Alternative certification programs (some of which offer teacher certification in as little as 3 months) will undoubtedly face the same issues with even less success. Fast track programs are currently gaining much attention and support by the federal government (Kumashiro, 2010). Programs like "Teach for America" claim that by attracting the most talented students to teaching they offer a quicker and thus more attractive option to certification. We are certain that our graduate program attracts many of the nation's best students. However, competency in science, as currently measured in secondary and post secondary institutions is unlikely to be accompanied by an understanding of the nature of science, and thus the situation risks leaving students in the awkward position of teaching science as they learned it (as well as facing the likely situation of not recognizing the need to re-construct what it means to understand or teach science). 
We recommend that teacher education programs addressing the sciences adopt a different framework to support the integration of theory and practice as recommended by McGoey and Ross (1999). We recommend formal mentorship programs that extend beyond graduation to help new teachers manage the practical issues that will arise as they attempt to integrate new ideas into their classroom pedagogy. Such an arrangement would also offer researchers classroom contexts to study the interaction between theory and practice. This longer-term approach, organized by university pre-service education programs, should support ongoing relationships between new instructors, supervising teachers, university instructors/researchers, and school administrators. Of course this proposition is more labor intensive than present practice; however, without this collaboration, we expect that any new conceptual framework (regarding how to teach) encountered in university courses or the current fast-track programs would give way to teaching strategies that are more expedient in the short run, but ineffective in the long.

Furthermore, given the often broad agendas in state and national testing initiatives, we are concerned about the role testing will play in impeding student understanding of science, the role of its models, and the implications for teaching. We are concerned that the tests and the curricula designed to meet the demand for higher performance on exams will convey to both pre-service and experienced teachers, and to their students, that the goal of science education is mastering the algorithm. These curricula will offer certain advantages, such as offering teachers an easy approach to judge the progress of students, and students a simple means to judge their own progress. However, with so much focus on outcomes, the saddest legacy of science education would be if we inadvertently produced another generation of students who in large part do not recognize the limitations and potential in the models scientists use to describe and predict Nature's behavior, or have the patience to struggle with building such an understanding.

\section{Conclusions}

Our experience with some of the nations' best pre-service teachers highlighted a number of problems that pose important challenges for science education and education in general. The challenge of conceptual change is not only relevant to the students' struggle to understand the models of science (i.e., its products), but also the nature of science (i.e., its process). For many of our students, deductions from a model such as Archimedes' principle did not look like an answer. For some of our students the principle did not even appear useful or coherent. Additionally, many of our students were unprepared for the mental exercise required to become proficient with models and their uses. Both are central goals highlighted in the National Science Education Standards (NRC1996) and A Framework for K-12 Science Education (NRC, 2012). If the concept of models troubles students committed to science education, then we can imagine how the distinction between models and observations is lost on the great majority of students who will not pursue science-related careers.

We were unprepared to address the extent to which science majors were separated from the nature of scientific thinking. The more we realized how extensive the gulf was with our students, the more we pushed to close the gap with a deeper look at how one principle could serve as a means to explore the epistemology of science. Our approach did have a positive but limited impact on developing in some students a richer understanding of models and NOS. However, our students were often unhappy with their new perspective because it directly challenged the way they had been taught to think about "answers" in science and the implications this would have on their teaching as well as their students' learning. We find that this state of affairs greatly limits the effectiveness of current pre-service science education programs and creates an unclear future for how shorter more aggressive fast-track certification programs will address this challenge.

Our students were very successful in an educational system that had reduced complex ideas in science to simple representations about the world, and were convinced that they had learned unfailing truths about their world. This competence was not sufficient for our students to deal with the conceptual problems that we offered them. Of greater concern, from the perspective of the goals of the course, was that the students' prior experience inside and outside the classroom hindered their study of NOS and created new problems which appropriately undermined their confidence in their command of the material and their ability to teach it effectively.

The models students explore in pre-college science courses are too often reduced to facts about the world that students must memorize, and that the connection between evidence and inference is insufficiently explored, if explored at all. This situation, more than any other, is likely to convince yet another generation of students that the goal of science education is accumulating and disseminating facts instead of supporting and nurturing a process that generates deeper understandings of their world, and more insidiously, leads to post-secondary programs that ignore these realities.

Our students' experiences revealed that they needed time to not only re-build their understanding of science, they 
needed time to evaluate and address the impact of their education in science. In turn they needed to consider the implications of a conceptual approach in their teaching. They needed to accommodate the fragility of their own understanding at the same time that they were considering how to prepare their students to be successful in a context that was antithetical to what we proposed. The structure of current pre-service programs does not seem well suited to meet these challenges. Our general view that certification programs should include longer mentorship programs is surfacing at a time when current policy seems to be pushing for shorter more expedient solutions especially for pre-service teachers (Kumashiro, 2010).

\section{References}

Abd-El Khalick, F., \& Lederman, N. G. (2000). Improving science teachers' conceptions of nature of science: A critical review of the literature. International Journal of Science Education, 22(7), 665-701. http://dx.doi.org/10.1080/09500690050044044

Aguirre, J. M., Haggerty, S. M., \& Linder, C. J. (1990). Student-teachers' conceptions of science, teaching, and learning: A case study in pre-service science education. International Journal of Science Education, 12(4), 281-390. http://dx.doi.org/10.1080/0950069900120405

Agung, S., \& Schwartz, M. S. (2007). Students' understanding of conservation of matter, stoichiometry and balancing equations in Indonesia. International Journal of Science Education, 29(13), 1679-1702. http://dx.doi.org/10.1080/09500690601089927

American Association for the Advancement of Science. (1989). Project 2061: Science for All Americans. Washington D.C.: AAAS.

Arons, A. (1990). A guide to introductory physics teaching. New York: Wiley.

Backhus, D. A., \& Thompson K. W. (2006). Addressing the nature of science in pre-service science teacher programs: Science educator perceptions. Journal of Science Teacher Education, 17, 65-81. http://dx.doi.org/10.1007/s10972-006-9012-9

Brown, D. E., \& Clement, J. (1989). Overcoming misconceptions via analogical reasoning: Abstract transfer versus explanatory model construction. Instructional Science, 18, 237-261. http://dx.doi.org/10.1007/BF00118013

Brown, J. S., Collins, A., \& Duguid, P. (1989). Situated cognition and the culture of learning. Educational Researcher, 18(1), 32-42. http://dx.doi.org/10.3102/0013189X018001032

Carpenter, S. (2012). Testing enhances the transfer of learning. Current Directions in Psychological Science, 21, 279-283. http://dx.doi.org/10.1177/0963721412452728

Case, R. (1997). The development of conceptual structures. In D. Kuhn, \& R. S. Siegler (Eds.), Carmichael's handbook of child development, 5th Edition: Vol. 2. Perception cognition and language. New York: McGraw Hill.

Champagne, A. B., Gunstone, R. F., \& Klopfer, L. E. (1985). Effecting changes in cognitive structures among physics students. In L. West, \& A. Pines (Eds.), Cognitive Structure and Conceptual Change (pp. 163-188). Orlando, FL: Academic Press.

Chi, M. T. H., \& Roscoe, R. D. (2002). The process and challenges of conceptual change. In M. Limon, \& L. Mason (Eds.), Reconsidering conceptual change: Issues in theory and practice (pp. 3-27). Dordrecht: Kluwer. http://dx.doi.org/10.1007/0-306-47637-1_1

Chinn, C. A., \& Brewer, W. F. (1993). The role of anomalous data in knowledge acquisition: A theoretical framework and implications for science instruction. Review of Educational Research, 63(1), 1-49. http://dx.doi.org/10.3102/00346543063001001

Chinn, C. A., \& Brewer, W. F. (1998). An empirical test of a taxonomy of responses to anomalous data in science. Journal of Research in Science Teaching, 35(6), 623-654. http://dx.doi.org/10.1002/(SICI)1098-2736(199808)35:6<623::AID-TEA3>3.0.CO;2-O

Coll, R. K., France, B., \& Taylor, I. (2005). The role of models and analogies in science education: Implications from research. International Journal of Science Education, 37(2), 183-198. http://dx.doi.org/10.1080/0950069042000276712

Corte, E. D. (2012). Constructive, self-regulated, situated, and collaborative learning: An approach for the acquisition of adaptive competence. Journal of Education, 192(2), 33-47. 
Cosgrove, M., \& Osborne, R. (1985). Lesson frameworks for changing children's ideas. In R. Osborne, \& F. P. Freyberg (Eds.), Learning in Science: The Implications of Children's Science (pp. 101-111). Portsmouth, NH: Heinemann.

Csikszentmihalyi, M., \& Rathunde, K. (1998). The development of the person: An experiential perspective on the ontogenesis of psychological complexity. In W. Damon (Ed.), \& R. Lerner (series Ed.), Handbook of child psychology: Theoretical models of human development (Vol. 5). New York: Wiley.

diSessa, A. A. (2006). A history of conceptual change research: Threads and fault lines. In R. K. Sawyer (Ed.), The Cambridge handbook of the learning sciences (pp. 265-281). Cambridge: Cambridge University Press.

diSessa, A. A. (2008). A bird's-eye view of the "pieces" vs. "coherence" controversy (from the "pieces" side of the fence). In S. Vosniadou (Ed.), International handbook of research on conceptual change (pp. 35-60). New York: Routledge.

Doucerain, M., \& Schwartz, M. S. (2010). Analyzing learning about conservation of matter in students while adapting to the needs of a school. Mind, Brain and Education, 4(3), 112-124. http://dx.doi.org/10.1111/j.1751-228X.2010.01090.x

Driver, R., Guesne, E., \& Tiberghien, A. (1985). Some features of children's ideas and their implications for teaching. In R. Driver, E. Guesne, \& A. Tiberghien (Eds.), Children's ideas in science (pp. 193-201). Milton Keynes: Open University Press.

Dunbar, K. (1995). How scientists really reason: Scientific reasoning in real-world laboratories. In R. J. Sternberg, \& J. Davidson (Eds.), Mechanisms of insight (pp. 365-395). Cambridge, MA: MIT press.

Durmus, J., \& Bayraktar, S. (2010). Effects of conceptual change texts and laboratory experiments on fourth grade students' understanding of matter and change concepts. Journal of Science Education Technology, 19, 498-504. http://dx.doi.org/10.1007/s10956-010-9216-9

Epstein, L. (2009). Thinking physics: Understanding practical reality (3rd ed.). San Francisco: Insight Press.

Epstein, L., \& Hewitt, P. G. (1981). Thinking physics. San Francisco: Insight Press.

Ericsson, K. A., Krampe, R. T., \& Tesch-Romer, C. (1993). The role of deliberate practice in the acquisition of $\begin{array}{llll}\text { expert performance. } & \text { Psychological } & \text { Review, }\end{array}$ http://dx.doi.org/10.1037/0033-295X.100.3.363

Fischer, K. W., \& Bidell, T. R. (2006). Dynamic development of action and thought. In W. Damon, \& R. M. Learner (Eds.), Handbook of child psychology: Theoretical models of human development (6th ed., Vol. 1, pp. 313-399). New York: Wiley. http://dx.doi.org/10.1002/dvdy.20917

Fischer, K. W., Bullock, D., Rotenberg, E. J., \& Raya, P. (1993). The dynamics of competence: How context contributes directly to skill. In R. Wozniak, \& K. W. Fischer (Eds.), Development in context: Acting and thinking in specific environments (pp. 93-117). Hillsdale, N.J.: Erlbaum.

Fischer, K. W., Yan, Z., \& Stewart, J. (2003). Adult cognitive development: Dynamics in the developmental web. In J. Valsiner, \& K. Connolly (Eds.), Handbook of developmental psychology (pp. 491-516). Thousand Oaks, CA: Sage.

Gericke, N., Hagberg, M., Jorde, D. (2013). Upper secondary students' understanding of the use of multiple models in biology textbooks-The importance of conceptual variation and incommensurability. Research in Science Education, 43(2), 755-780. http://dx.doi.org/10.1007/s11165-012-9288-z

Gilbert, J. K., Pietrocola, M., Zylbersztajn, A., \& Franco, C. (2000). Science and education: Notions of reality, theory and model. In J. K. Gilbert, \& C. Boulter (Eds.), Developing models in science education (pp. 19-40). Dordrecht: Kluwer Academic. http://dx.doi.org/10.1007/978-94-010-0876-1_2

Granott, N., \& Parziale, J. (Eds.). (2002). Microdevelopment: Transition processes in development and learning. Cambridge, U.K.: Cambridge University Press. http://dx.doi.org/10.1017/CBO9780511489709

Grosslight, L., Unger, C., Jay, E., \& Smith, C. L. (1991). Understanding models and their use in science: Conceptions of middle and high school students and experts. Journal of Research in Science Teaching, 28(9), 799-822. http://dx.doi.org/10.1002/tea.3660280907

Hestenes, D. (1998). Who needs physics education research!? American Journal of Physics, 66, 465-467. http://dx.doi.org/10.1119/1.18898

Hewitt, P. G. (2010). Conceptual physics (11th ed.). Boston, MA: Addison-Wesley. 
Hewson, P. W., \& Hewson, M. G. (1984). The role of conceptual conflict in conceptual change and the design of science instruction. Instructional Science, 13, 1-13. http://dx.doi.org/10.1007/BF00051837

Hipkins, R. (2005). Teaching the 'nature of science': Modest adaptations or radical reconceptions? International Journal of Science Education, 27(2), 243-254. http://dx.doi.org/10.1080/0950069042000276758

Howe, C., Devine, A., \& Tavares, J. T. (2013). Supporting conceptual change in school science: A possible role for tacit understanding. International Journal of Science Education, 35(5), 864-883. http://dx.doi.org/10.1080/09500693.2011.585353

Kim, E., \& Pak, S. J. (2002). Students do not overcome conceptual difficulties after solving 1000 traditional problems. American Journal of Physics, 70(7), 759-765. http://dx.doi.org/10.1119/1.1484151

Kuhn, T. S. (1962). The structure of scientific revolutions. Chicago: University of Chicago Press. http://dx.doi.org/10.1063/1.1746564

Kumashiro, K. (2010). Seeing the bigger picture: Troubling movements to end teacher education. Journal of Teacher Education, 61(1-2), 56-65. http://dx.doi.org/10.1177/0022487109347318

Lave, J. (1993). Word problems: A microcosm of theories of learning. In P. Light, \& G. Butterworth (Eds.), Context and cognition: Ways of learning and knowing (pp. 74-92). Hillsdale, N.J.: Lawrence Erlbaum Associates.

Le Grand, H. E. (1988). Drifting continents and shifting theories. Cambridge, MA: Cambridge University Press.

Lederman, N. G. (1992). Students' and teachers' conceptions of the nature of science: A review of the research. Journal of Research in Science Teaching, 29(4), 331-359. http://dx.doi.org/10.1002/tea.3660290404

Lee, G., \& Byun, T. (2012). An explanation for the difficulty of leading conceptual change using a counterintuitive demonstration: The relationship between cognitive conflict and responses. Research in Science Education, 42, 943-965. http://dx.doi.org/10.1007/s11165-011-9234-5

Limón, M. (2001). On the cognitive conflict as an instructional strategy for conceptual change: A critical appraisal. Learning and Instruction, 11(4-5), 357-380. http://dx.doi.org/10.1016/S0959-4752(00)00037-2

Loverude, M. E., Kautz, C. H., \& Heron, P. R. L. (2003). Helping students develop an understanding of Archimedes' principle, Part I: Research on student understanding. American Journal of Physics, 71(11), 1178-1187. http://dx.doi.org/10.1119/1.1607335

McDermott, L. C., \& Redish, E. F. (1999). RL-PER1: Resource letter on physics education research. American Journal of Physics, 67(9), 755-767. http://dx.doi.org/10.1119/1.19122

McGoey, J., \& Ross, J. (1999). Research, practice, and teacher internship. Journal of Research in Science Teaching, 36(2), 117-120. http://dx.doi.org/10.1002/(SICI)1098-2736(199902)36:2<117::AID-TEA1>3.0.CO;2-G

McKeough, A., \& Lupart, J. (1995). Teaching for transfer: Fostering generalization in learning. Hillsdale, NJ: Erlbaum.

National Research Council. (1996). National science education standards. Washington DC: National Academy Press.

National Research Council. (1999). How people learn: Brain, mind, experience, and school. Washington, DC: National Academy Press.

National Research Council. (2012). A framework for K-12 science education: Practices, crosscutting concepts, and core ideas. Washington, DC: The National Academies Press.

Nussbaum, J., \& Novick, N. (1982). Alternative frameworks, conceptual conflict, and accommodation: Toward a principled teaching strategy. Instructional Science, 11, 183-200. http://dx.doi.org/10.1007/BF00414279

Perkins, D. N., \& Solomon, G. (1989). Rocky roads to transfer: Rethinking mechanisms of a neglected phenomenon. Educational Psychologist, 24, 113-142. http://dx.doi.org/10.1207/s15326985ep2402_1

Philippi, K. H. (2010). An examination of student understanding of the use of models in science and conceptual understanding of electricity and magnetism. University of New Orleans, New Orleans.

Piaget, J. (1964). Development and learning. In R. E. Ripple, \& V. N. Rockcastle (Eds.), Piaget Rediscovered. New York: Cornell University Press.

Piaget, J. (1985). The equilibration of cognitive structures: The central problem of intellectual development (T. 
Brown, \& K. J. Thampy, 2nd Trans.). Chicago: University of Chicago Press. (Original work published in 1975).

Pintrich, P. R., Marx, R. W., Boyle, R. A. (1993). Beyond cold conceptual change: The role of motivational beliefs and classroom contextual factors in the process of conceptual change. Review of Educational Research, 63(2), 167-199. http://dx.doi.org/10.3102/00346543063002167

Posner, G. J., Strike, K. A., Hewson, P. W., \& Gertzog, W. A. (1982). Accommodation of a scientific conception: Toward a theory of conceptual change. Science Education, 66, 211-227. http://dx.doi.org/10.1002/sce.3730660207

Potgieter, M., Harding, A., \& Engelbrecht, J. (2008). Transfer of algebraic and graphical thinking between mathematics and chemistry. Journal of Research in Science Teaching, 45(2), 197-218. http://dx.doi.org/10.1002/tea.20208

Rogoff, B. (1990). Apprenticeship in thinking. New York: Oxford University Press.

Sadler, P. M. (1992). The initial knowledge state of high school astronomy students. Graduate School of Education. Unpublished Thesis. Cambridge, MA, Harvard.

Salomon, G., \& Perkins, D. N. (1989). Rocky roads to transfer: Rethinking mechanisms of a neglected phenomenon. Educational Psychologist, 24(2), 113-142. http://dx.doi.org/10.1207/s15326985ep2402_1

Schwartz, M. S. (2009). Cognitive development and learning: Analyzing the building of skills in classrooms. Mind, Brain and Education, 3(4), 198-208. http://dx.doi.org/10.1111/j.1751-228X.2009.01070.x

Schwartz, M. S., \& Dawson, T. (2011). Standards \& assessments: The role of depth versus breadth in student success. White Paper for the Texas Education Reform Foundation.

Schwartz, M. S., \& Sadler, P. S. (2007). Empowerment in science curriculum development: A microdevelopmental approach. International Journal of Science Education, 29(18), 987-1017. http://dx.doi.org/10.1080/09500690600931053

Schwartz, M. S., Sadler, P. S., Sonnert, G., \& Tai, R. H. (2009). Depth versus breadth: How content coverage in high school science courses relates to later success in college science coursework. Science Education, 93(5), 798-826. http://dx.doi.org/10.1002/sce.20328

Scott, P., Asoko, H., \& Leach, J. (2007). Student conceptions and conceptual learning in science. In S. K. Abell, \& N. G. Ledermann (Eds.), Handbook of research on science education (pp. 31-56). Mahwah, NJ: Lawrence Erlbaum.

Siegler, R. S. (1998). Children's thinking (3rd ed.). Upper Saddle River, NJ: Prentice Hall.

Strike, K. A., \& Posner, G. J. (1992). A revisionist theory of conceptual change. In R. Duschl, \& R. Hamilton (Eds.), Philosophy of Science, Cognitive Psychology, and Educational Theory and Practice (pp. 147-176). Albany, NY: SUNY.

Suping, S. M. (2003). Conceptual change among students in science [Electronic Version]. ERIC Digest, Retrieved from http://www.ericdigests.org/2004-3/change.html

Taber, K. S. (2009). Progressing science education: Constructing the scientific research programme into the contingent nature of learning science. Dordrecht: Springer.

Treagust, D. F., Chittleborough, G. D., \& Mamiala, T. L. (2002). Student understanding of the role of scientific models in learning science. International Journal of Science Education, 24(4), 357-368. http://dx.doi.org/10.1080/09500690110066485

Turcotte, S. (2012). A computer-supported collaborative inquiry on buoyancy: A discourse analysis supporting the "pieces" position on conceptual change. Journal of Science Educational Technology, 2012(21), 808-825. http://dx.doi.org/10.1007/s10956-012-9368-x

Tyson, L. M., Venville, G. J., Harrison, A. G., \& Treagust, D. F. (1997). A multidimensional framework for interpreting conceptual change events in the classroom. Science Education, 81(4), 387-404. http://dx.doi.org/10.1002/(SICI)1098-237X(199707)81:4<387::AID-SCE2>3.0.CO;2-8

Vosniadou, S. (2007). The conceptual change approach and its re-framing. In S. Vosniadou, A. Baltas, \& X. Vamvakoussi (Eds.), Reframing the conceptual change approach in learning and instruction (pp. 1-15). Oxford, UK: Elsevier.

Vosniadou, S. (Ed.). (2008). International handbook of research on conceptual change. New York: Routledge. 
Vosniadou, S., Baltas, A., \& Vamvakoussi, X. (Eds.). (2007). Reframing the conceptual change approach in learning and instruction. Oxford, UK: Elsevier.

Vygotsky, L. S. (1978). Mind in society: The development of higher psychological processes. Cambridge, MA: Harvard University Press.

Willems, P. P. (2005). A comparison of two learning environments on students' learning of an instructional strategy. Journal of College Teaching \& Learning, 2(10), 79-85.

Yan, Z., \& Fischer, K. (2002). Always under construction dynamic variations in adult cognitive microdevelopment. Human Development, 45(3), 141-160. http://dx.doi.org/10.1159/000057070

\section{Notes}

Note 1. We take the definition of an algorithm to be a mathematical formula that relates a number of variables.

Note 2. Students signed release forms indicating that the videos were to document the process for later study, analysis and publication of our work. The release form is on file and available upon request.

Note 3. Triple beam balance: A one-pan balance with three separate beams that allow for measuring grams, tens of grams or hundreds of grams. Picture at: http://www.physics.smu.edu/ scalise/apparatus/triplebeam/

\section{Appendices}

\section{Appendix A. Floating and Sinking Questionnaire I}

1. What is the density of water?
a) 0 grams per cc
b) 1 gram
c) 1 gram per cc
d) 10 grams per cc

2. A small solid cube of unknown material has a mass of 10 grams. It has a volume of $4 \mathrm{cc}$. The material has a density of:
a) 2.5 grams per cc
b) 40 grams per cc
c) 25 grams per cc
d) .25 grams per cc

3. If the cube in question 2 were placed in a swimming pool, it would:
a) sink
b) float
c) stabilize somewhere between the surface and the bottom
d) be impossible to predict what the cube would do

4. An unknown material in the shape of a solid cube has a density of 2 grams per cc. The volume of the cube is $40 \mathrm{cc}$. Calculate the mass of the cube and choose the correct answer below.
a) 80 grams
b) 0.5 grams
c) 2 grams
d) 20 grams

5. If the cube in question 4 were not soluble in water and were placed in a large tub of water, it would:
a) sink
b) float
c) stabilize somewhere between the surface and the bottom 
d) be impossible to predict what the cube would do

6. An unknown solid material in the shape of a sphere has a volume of $30 \mathrm{cc}$. The sphere has a mass of 15 grams. If the material were not soluble in water and were placed in a large tub of water, it would:
a) $\operatorname{sink}$
b) float
c) stabilize somewhere between the surface and the bottom
d) be impossible to predict what the cube would do

Appendix B. Floating and Sinking Questionnaire II

1. You have two, identical, large pans completely filled with water. Into one of these pans you place a small solid block of pine wood. Into the other pan, you place an identically sized and shaped block, but one of solid aluminum. The amount of water displaced (pushed out of the pan) is
a) greater for the wood.
b) greater for the aluminum.
c) the same for both.

2. The water displaced by the block of wood in Question 1 has a
a) weight equal to the block's weight.
b) volume equal to the block's volume.
c) weight and volume equal to the block's weight and volume.
d) weight and volume different from the block's weight and volume.

3. The water displaced by the block of aluminum in Question 1 has a

a) weight equal to the block's weight.

b) volume equal to the block's volume.

c) weight and volume equal to the block's weight and volume.

d) weight and volume different from the block's weight and volume.

4. (The following question is a "thought experiment.") You have one large pan completely filled with water, with a long thin wire attached securely to the bottom of the pan. Without disturbing the water you secure the wire to a small hook at the bottom of the same small, solid block of pine wood as in Question 1, insuring that the block of wood is completely submerged beneath the surface of the water that remains in the pan. The amount of water displaced by the block has a

a) weight equal to the block's weight.

b) volume equal to the block's volume.

c) weight and volume equal to the block's weight and volume.

d) weight and volume different from the block's weight and volume.

5. Imagine that you attach a very solid rock to the bottom of a spring scale and lower it until the whole rock is just beneath the surface of the water. The scale would read
a) less than...
b) more than...
c) the same as...

...when the rock was above the water (i.e., in the air).

6 . As the rock in the preceding problem is lowered deeper and deeper into the water, the scale will read

a) less than...

b) the same as...

c) more than...

...the scale reading when the entire rock is just beneath the surface.

7. Could a cruise ship float in a bathtub if the bathtub were just big enough to hold the entire ship and was filled 
with water before the ship was placed in it?

a) The cruise ship would float.

b) The cruise ship would touch bottom.

c) It is impossible to tell from the information provided.

8. A container filled to the brim with water and a similar container filled to the brim with water in which a block of wood is floating are each weighed. Which of the following is true, $a, b$, or $c$ ?

a) The container with only the water would weigh more.

b) The container with the water and the block of wood would weigh more.

c) Both containers would weigh the same amount.

9. A glass of water is brim-full of ice-cold water with ice cubes floating in it. As the ice cubes melt, the water level in the glass

a) will go down.

b) will go up.

c) will not change.

10. A canoe containing an iron weight is floating in a swimming pool. If the weight is thrown overboard into the pool, the water level in the pool will
a) rise.
b) fall.
c) not change.

\section{Copyrights}

Copyright for this article is retained by the author(s), with first publication rights granted to the journal.

This is an open-access article distributed under the terms and conditions of the Creative Commons Attribution license (http://creativecommons.org/licenses/by/3.0/). 